\title{
Comparative Histological Study of Parenchymal Arrangements in Three Orders of Reptilian Livers
}

\section{Hideo Akiyoshi ${ }^{1 *}$, Asuka Inoue-Matsuo ${ }^{1}$ and Itaru Onodera ${ }^{2}$}

${ }^{1}$ Department of Biological Science, Faculty of Life and Environmental Science, Shimane University, 1060 Nishikawatsu, Matsue 690-8504, Japan ${ }^{2}$ Department of Legal Medicine, Ehime University Graduate School of Medicine, Shitsukawa, Toon, Ehime 791-0295, Japan

\begin{abstract}
This study presented detailed descriptions of parenchymal arrangements in the livers of 23 reptilian species using light microscopy, and extensively discussed this from a phylogenetic viewpoint. Hepatocyte sinusoidal structures (HSS) were classified into three different types: (I) the several-cell-thick plate type, (II) two-cell-thick plate type, and (III) one-cell-thick plate type. Parenchymal arrangements showed either the combined two- and one-cell-thick plate type or one-cell-thick plate type, whereas the sea snake in the sub-order Serpentes showed the several-cell-thick plate type. In the order Testudines, peripheral sinusoids near terminal portal veins were tortuous, becoming straighter toward terminal central veins. Melanomacrophages (MMs) were observed in sinusoidal capillaries in the order Testudinata, Crocodilia, and Squamata, but not in the sub-order Serpentes (except for the sea snake). This study showed that the architecture of the parenchymal arrangement was related to the phylogenetic relationship, whereas the distribution of MMs may not be. The MMs systems of turtles, alligators, and sea snakes, whose place of main habitation is underwater, may have adapted according to ecological and behavioral patterns. Based on the hepatic architecture of parenchymal arrangements and the distribution of MMs, it was suggested that reptilian livers acquired the division of three zones in the acinus.
\end{abstract}

Keywords: Liver; Reptilian; Parenchymal arrangements; Melanomacrophages; Phylogeny; Evolution

\section{Introduction}

The structural and functional unit of the liver is the acinus, which contains the hepatic lobule and portal triad (also called Glisson's sheath). The hepatic lobule consists of hepatocytes, which are the functional center of the liver and in which hepatocyte sinusoidal structures (HSS) are formed. Sinusoids are capillary networks that are localized in the space between hepatic plates in which hepatocytes are arranged [1,2]. Parenchymal arrangements are directed from the afferent (portal vein) of the lobule to its efferent (central vein) along the lengths of the hepatic plates, and Rappaport divided them into three arbitrary zones (zones 1, 2, and 3) [3]. Parenchymal arrangements form associations that are structurally similar in all parts of the vertebrate liver; however, a number of livers show structural and functional heterogeneities in adults with even phylum [4-6].

In mammals, hepatic plates line simple-layered hepatocytes, and parenchymal arrangements are the one-cell-thick plate type [7]. Amphibians have either the combined two- and one-cell-thick plate type or one-cell-thick plate type [6]. In fishes, hepatic plates line multilayered hepatocytes, the so-called solid or tubular types [4,5]. Akiyoshi and Inoue classified the structures of parenchymal arrangements into three different types in teleost livers: (I) the cord-like form, (II) tubular form, and (III) solid form [5]. In several vertebrates, a relationship has been identified between HSS and phylogeny; however, this has not yet been examined in any order in reptilians.

Reptiles are classified as amniotes, along with birds and mammals. They breathe air and do not lay eggs underwater even though many species live in or around water. Reptilians have been grouped into four orders: Testudines, Sphenodontia, Squamata, and Crocodilia. Although Testudines (turtles) are omnivorous, many have highly specialized diets. Turtles are abundant in the tropics, but are also diverse in temperate regions. Sphenodontia is an order of lizard-like reptiles that includes only one living genus, the New Zealand tuatara. Squamates are the largest reptile order and have been divided into Lacertilia (lizards and amphisbaenians) and Ophidia (snakes). They are present on every continent, except for Antarctica, have invaded marine environments, and have also diversified into many different specialized terrestrial forms, including burrowers and gliders. Crocodilia includes true crocodiles (family Crocodylidae), alligators and caimans (family Alligatoridae), and gharial and false gharial (family Gavialidae). Crocodilians are mainly found in the lowlands in the tropics; however, alligators also live in the southeastern part of the United States and the Yangtze River in China. They are ectotherms; their internal temperature varies according to the ambient environment.

In heterothermic vertebrates, aggregations of pigmented cells termed melanomacrophages (MMs) have been identified in the livers of some fishes [8,9], amphibians [10-13], and reptiles [1417]. Extracutaneous melanin-containing cells have been detected in various tissues and organs such as the liver, spleen, kidney, and lungs $[9,18,19]$. MMs of the liver are mainly localized in the endothelial walls of sinusoids anchored to endothelial cells that sometimes protrude into the lumen [13]. While the existence of MMs in many evolutionarily divergent orders of heterothermic vertebrates has not yet been determined, it is surmised that these cells are beneficial for poikilotherms, since they are not present in birds or mammals [15]. In order to demonstrate the relationship between the structure of the liver and phylogenic status, livers of 23 reptilian species were examined using light microscope, and subjected the data obtained to phylogenic analysis. The study focused on the parenchymal arrangements of HSS formations and the distribution of MMs, and also discussed the division of zones in the acinus.

*Corresponding author: Hideo Akiyoshi, Department of Biological Science, Faculty of Life and Environmental Science, Shimane University, 1060 Nishikawatsu, Matsue 690-8504, Japan, Tel: +81-852-32-6440; E-mail: akiyoshi@life.shimane-u.ac.jp

Received October 31, 2015; Accepted December 04, 2015; Published December 11,2015

Citation: Akiyoshi H, Inoue-Matsuo A ,Onodera I (2015) Comparative Histological Study of Parenchymal Arrangements in Three Orders of Reptilian Livers. J Phylogen Evolution Biol 4: 161. doi:10.4172/2329-9002.1000161

Copyright: ( $) 2015$ Akiyoshi $\mathrm{H}$, et al. This is an open-access article distributed under the terms of the Creative Commons Attribution License, which permits unrestricted use, distribution, and reproduction in any medium, provided the original author and source are credited. 


\section{Materials and Method}

The study protocol was approved by the Animal Ethics Committee of Shimane University, and was conducted in strict adherence with the guidelines for the care and use of research animals as approved by W.H.O [20].

\section{Sample collection}

The livers of 23 different reptilian species were used in this comparative morphological study. Using hand nets, we collected 13 species in Shimane Prefecture, and 9 species in the Iriomote Islands in Okinawa Prefecture. In order to eliminate the influence of seasonal changes or growth, all specimens were both male and female in the adult stage, and reptiles were caught between April and October in each locality between 2005 and 2014. Three to five specimens were sampled, except for Alligator (Alligator mississippiensis), for which one sample was supplied by Dr. Iguchi at the National Institute for Basic Biology.

Animals were euthanized by injecting sodium pentobarbital into the supravertebral vein and, after muscular relaxation, lateral incision lines were made on the left and right body wall to remove the skin, ventral body wall, and ribs, thereby exposing the liver. The phylogenetic relationships of the Reptilian Class, comprising three orders of reptilians: 4 Testudines, 18 Squamata, and 1 Crocodilia species, is shown in Table 1.

\section{Histology}

Perfusion fixation was selected as the method of fixation because the structural relationship in the liver is obscured by congestion when it is immersion-fixed. The portal vein to the right lobe was tied off in situ, and the liver was then removed from the body cavity and connected to a peristaltic pump (H.R. Flow Inducer, Watson Marlow Limited, England). Livers were perfusion-fixed via the heart with $4 \%$ paraformaldehyde buffered at $\mathrm{pH} 7.4$ with $0.1 \mathrm{M}$ phosphate for 15 min, cut into small pieces, and immersed in the same solution at $4^{\circ} \mathrm{C}$ for 3 days. The specimens were rinsed, dehydrated, and embedded in paraffin. Four-micrometer-thick serial sections were obtained, some of which were stained with hematoxylin and eosin, while others were stained with Azan for morphometric analyses. Sections were observed and photographed with a BX51 photomicroscope (Olympus, Tokyo, Japan).

\section{Morphometry}

Morphometry is the evaluation of forms and, in histology, describes measurements made from two-dimensional sections. Liver sections stained with Azan for hepatic cells were subjected to a morphometric analysis. We used a computerized image analysis system comprised of

\begin{tabular}{|l|l|l|c|}
\hline Order & Suborder & Family & Species number \\
\hline Testudines & & Geoemydidae & 2 \\
\hline & & Emydidae & 1 \\
\hline Squamata & Lacertilia & Trionychidae & 1 \\
\hline & & Gekkonidae & 2 \\
\hline & & Agamidae & 1 \\
\hline & & Scincidae & 3 \\
\hline & Serpentes & Lacertidae & 3 \\
\hline & & Colubridae & 6 \\
\hline & & Elapidae & 1 \\
\hline Crocodilia & & Viperidae & 2 \\
\hline & & Alligatoridae & 1 \\
\hline
\end{tabular}

Table 1: Summary of the phylogenetic relationships in reptilian class.

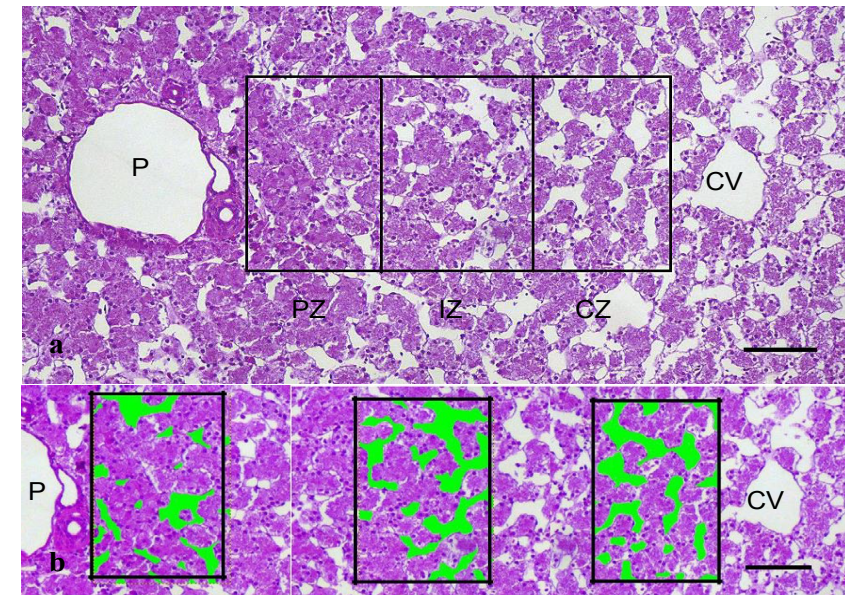

Figure 1: Light micrographs of the liver. Low magnification light micrographs of hepatic lobule in livers. (a) A portal triad $(P)$ and central vein $(C V)$ are seen in the hepatic lobule, and consists of both hepatocytes and sinusoidal blood capillary networks, in which HSS are formed. The percentage extension of sinusoidal areas was quantified in three different zones: the periportal zone (PZ) surrounding the portal triad, interstitial zone (IZ) between the portal and central veins, and pericentral zone $(C Z)$ around the central vein in hepatic lobules. (b) The three zones (PZ, IZ, CZ) were captured on digitalized images at a final magnification of 200X. Red-eared slider (Trachemys scripta elegans). Scale bar $=100 \mu \mathrm{m}$.

a photomicroscope (Olympus BX51), digital camera (Olympus DP70), and Lumina Vision software (Mitani Corporation, Tokyo, Japan). Lumina Vision is a Microsoft Windows XP application for the semiautomated quantitative analysis of fixed histological sections. This software performs automatic measurements of areas defined using an interactive threshold editing function to give a colored overlay that marks which pixels in the image are to be measured. In the present study, the percentage extension of sinusoidal areas was quantified in three different zones: the periportal zone (PZ) surrounding the portal triad, interstitial zone (IZ) between the portal and central veins, and pericentral zone $(\mathrm{CZ})$ around the central vein in hepatic lobules (Figure 1a). At least six areas, 6 random fields in each section, were captured on digitalized images at a final magnification of 200X (Figure 1b). The analysis of each species was performed on 36 randomly chosen zones in three specimens.

\section{Results}

The distribution of HSS and MMs in the livers of 23 reptilians is summarized in Table 2 . They exhibited various histological features, and many resembled mammalian livers, but some species were different. In all reptilian livers, the acinus was demarcated by connective tissue septa, shown as the portal triad (portal tract), which contains bile ducts and portal and arterial vessels. These vessels and ducts were surrounded by connective tissue. The hepatic lobules consisted of hepatocytes and sinusoidal blood capillary networks, in which HSS formed (Figure 1a). Sinusoids were localized in the space between hepatic plates in which hepatocytes were arranged.

\section{HSS (Hepatocyte sinusoidal structure)}

Following cardiac perfusion fixation, hepatic sinusoids were cleared of blood cells and the definition of HSS was enhanced. Depending on the percentage of hepatic sinusoids per unit area, as measured by morphometry, the HSS of reptilian livers were divided into the following three classes: class I (percentage 5 to $<15$ ), class II (percentage 15 to $<25$ ), and class III (percentage $\geq 25$ ). HSS were classified into 


\begin{tabular}{|c|c|c|c|c|c|c|}
\hline \multirow[t]{2}{*}{ Species } & \multicolumn{3}{|c|}{ HSS } & \multicolumn{3}{|c|}{ MMS Distribution } \\
\hline & PZ & $\cdot \mathbf{I Z}$ &. $\mathrm{CZ}$ &.$P Z$ & .12 & $\mathbf{C Z}$ \\
\hline \multicolumn{7}{|l|}{ Testudines } \\
\hline \multicolumn{7}{|l|}{ Geoemydidae } \\
\hline Mauremys reevesi & 2 & 3 & 3 & $2+$ & $2+$ & $2+$ \\
\hline Mauremys japonica & 2 & 3 & 3 & - & $2+$ & $2+$ \\
\hline \multicolumn{7}{|l|}{ Emydidae } \\
\hline Trachemys scripta elegans & 2 & 3 & 3 & $3+$ & $1+$ & - \\
\hline \multicolumn{7}{|l|}{ Trionychidae } \\
\hline Pelodiscus sinensis & 2 & 3 & 3 & $1+$ & $1+$ & $1+$ \\
\hline \multicolumn{7}{|l|}{ Squamata } \\
\hline \multicolumn{7}{|l|}{ Lacertilia } \\
\hline \multicolumn{7}{|l|}{ Gekkonidae } \\
\hline Hemidactylus frenatus & 2 & 3 & 3 & $3+$ & $3+$ & $3+$ \\
\hline Gekko japonicas & 2 & 3 & 3 & - & $1+$ & - \\
\hline \multicolumn{7}{|l|}{ Agamidae } \\
\hline Japalura polygonata ishigakiensis & 2 & 3 & 3 & - & $1+$ & $1+$ \\
\hline \multicolumn{7}{|l|}{ Scincidae } \\
\hline Scincella boettgeri & 2 & 3 & 3 & $1+$ & $1+$ & $1+$ \\
\hline Plestiodon kishinouyei & 3 & 3 & 3 & $3+$ & $3+$ & $3+$ \\
\hline lestiodon japonicas & 3 & 3 & 3 & $1+$ & $1+$ & $1+$ \\
\hline \multicolumn{7}{|l|}{ Lacertidae } \\
\hline Takydromus smaragdinus & 3 & 3 & 3 & - & $1+$ & - \\
\hline Takydromus dorsalis & 3 & 3 & 3 & - & $2+$ & - \\
\hline Takydromus tachydromoides & 3 & 3 & 3 & - & $1+$ & $1+$ \\
\hline \multicolumn{7}{|l|}{ Serpentes } \\
\hline \multicolumn{7}{|l|}{ Colubridae } \\
\hline Elaphe climacophora & 3 & 3 & 3 & - & - & - \\
\hline Elaphe quadrivirgata & 3 & 3 & 3 & - & - & - \\
\hline laphe taeniura schmackeri & 3 & 3 & 3 & - & - & - \\
\hline Hebius vibakari & 3 & 3 & 3 & - & - & - \\
\hline Dinodon orientale & 3 & 3 & 3 & - & - & - \\
\hline Rhabdophis tigrinus & 3 & 3 & 3 & - & - & - \\
\hline \multicolumn{7}{|l|}{ Elapidae } \\
\hline Hydrophis melanocephalus & 1 & 1 & 1 & - & $1+$ & $1+$ \\
\hline \multicolumn{7}{|l|}{ Viperidae } \\
\hline Protobothrops elegans & 2 & 3 & 3 & - & - & - \\
\hline Gloydius blomhoffii & 2 & 3 & 3 & - & - & - \\
\hline \multicolumn{7}{|l|}{ Crocodilia } \\
\hline \multicolumn{7}{|l|}{ Alligatoridae } \\
\hline Alligator mississippiensis & 2 & 2 & 2 & $2+$ & $2+$ & $2+$ \\
\hline
\end{tabular}

Table 2: Summary of the expression levels of hepatocyte sinusoidal structures and Melanomacrophages distribution in livers of reptilian species. Hepatocyte sinusoidal structures Melanomacrophages distribution.

HSS: Hepatocyte sinusoidal structure: (1) several-cell-thick plate type, (2) two-cellthick plate type, (3): one-cell-thick plate type. Melanomacrophages distribution: $(-)$ do not exist, $(1+)$ small size, $(2+)$ moderate size, $(3+)$ large size. PZ: Periportal zone surrounding the portal triad, IZ: Interstitial zone between the portal and central veins, CZ: Pericentral zone around the central vein.

three different types: (I) the several-cell-thick plate type, (II) two-cellthick plate type, and (III) one-cell-thick plate type. Histologically, class I showed the several-cell-thick plate type, with the major part of the hepatocyte lining being multi-layered. Hepatic sinusoids were narrow with short tortuous capillaries (Figure 2a). In class II, showing the two-cell-thick plate type, most of the hepatocyte lining was doublelayered. Sinusoidal capillaries were narrow with irregularly shaped sinusoids appearing throughout the interstices between hepatic plates. Three to four hepatocytes surrounded a sinusoidal capillary (Figure 2b). Class III showed the one-cell-thick plate type, and most of the hepatocyte lining was simple-layered. Hepatic sinusoids were enlarged with straight capillaries connecting along the afferent-efferent axis of hepatic lobules (Figure 2c).

In the order Testudines, HSS showed the combined one- and twocell-thick plate types. PZ was the two-cell plate type, whereas IZ and $\mathrm{CZ}$ were the one-cell plate type and sinusoidal capillaries were enlarged (Figure 2d). Peripheral sinusoids near terminal portal veins were tortuous, becoming straighter in the remainder of their course toward terminal central veins.

In the order Squamata, traditional HSS were the one-cell-thick plate type, the mammalian form; it was detected in the suborder Serpentes (except for the genus Hydrophis) and some of the order Squamata (Figure 2e). Another form showed the combined two- and one-cell-thick plate type, and was observed in the suborder Lacertilia, Gekkonidae and Agamidae families. PZ and IZ were the two-cell plate types, whereas $\mathrm{CZ}$ was the one-cell plate type and the sinusoidal capillaries were enlarged. The Black-headed sea snake (genus Hydrophis) showed the several-cell-thick plate type, and sinusoidal capillaries were narrow with short tortuous capillaries (Figure 2a). Crocodilia showed the twocell-thick plate type. The sinusoidal capillaries were narrow with short tortuous capillaries.

\section{Distribution of MMs}

This study on the livers of 23 reptilian species revealed the distribution of MMs in the three zones (PZ, IZ, and CZ) of the afferentefferent axis of the acinus. MMs, containing prominent yellow to brown compound cytoplasmic phagosomes, formed part of the lining of the sinusoids, protruded into the sinusoidal lumen; they were also located in the hepatic parenchyma. However, MMs showed numerical, sizeable, and locational heterogeneities related to their phylogenetic order. The combination patterns of the location of MMs were classified into three types: (A) PZ, IZ, and CZ, (B) PZ and IZ, and (C) IZ and CZ. Histologically, category A showed the three-zone location type, with MMs being widely located in the acinus (Figure $2 \mathrm{e}$ and $2 \mathrm{f}$ ). In category $\mathrm{B}, \mathrm{MMs}$ were situated in the $\mathrm{PZ}$ and IZ (Figure 2d). Category $\mathrm{C}$ showed IZ and CZ (Figure 2g).

In the order Testudines, the distribution of MMs was category $B$, they were observed in sinusoidal capillaries, and various sizes existed (Figure 2d). In the order Squamata, MMs were observed in the suborder Lacertilia, but not in the sub-order Serpentes (except for the genus Hydrophis; the Black-headed sea snake). In the suborder Lacertilia, the distribution of MMs was the category B or C type, and the size of MMs was small. In the genera Hemidactylus and Plestiodon, the distribution of MMs was the category A type. MMs were larger and widely observed in the sinusoidal capillaries. In the Black-headed sea snake, the distribution of MMs was the category $\mathrm{C}$ type, and they were smaller and few in number in the sinusoids. In the order Crocodilia, the distribution of MMs was the category A type, they were observed in brown cytoplasmic phagosomes, they were of a moderate size in sinusoidal capillaries.

\section{Discussion}

This study is the first to phylogenically investigate reptilian livers. We attempted to identify the relationship between the distribution of HSS and MMs, and made a comparison with phylogenic development.

\section{HSS (Hepatocyte sinusoidal structure)}

HSS are physiologically important, not only because hepatocytes take up large molecules from sinusoids, but also because a large number of macromolecules are secreted into sinusoids [1]. Previous studies reported that the HSS of some lower vertebrates had a similar 
structure to those of normal humans, while others were modified in a more primitive form $[5,6,21]$. In mammals and higher vertebrates, hepatocytes are in close contact with sinusoidal capillaries that form a dense network, and hepatic plates line simple-layered hepatocytes, the so-called one-cell-thick plate's type [7]. In amphibians, HSS have been classified into three different types: (I) the several-cell-thick plate type, (II) two-cell-thick plate type, and (III) one-cell-thick plate type, with the traditional form being the combined two- and one-cell-thick plate type [6]. In contrast, teleost livers have an undeveloped network $[5,7,22]$. Akiyoshi and Inoue classified HSS into three different types: (I) the cord-like form, (II) tubular form, and (III) solid form in teleost livers. Furthermore, portal triads differed in other vertebrates, with four types being identified; (a) the biliary-isolated type, (b) biliaryarterial tract type, (c) biliary-venous tract type, and (d) portal tract type (biliary-arterial-venous tract type) [5].

Our study of 23 species led to the classification of the HSS of reptilian livers into three different types: (I) the several-cell-thick plate type, (II) two-cell-thick plate type, and (III) one-cell-thick plate type. The traditional form was the one-cell-thick plate type, and was observed in some species in the order Squamata. Another form was the combined two- and one-cell-thick plate type, and was observed in the order Testudines, and some species of the order Squamata. Crocodilia showed the two-cell-thick plate type. The expression of HSS exhibited heterogeneities related to the phylogenetic order. In contrast, the portal triads in all reptilian livers showed the same structures as in mammals, which contains bile ducts and portal and arterial vessels, as observed in mammals. We revealed that hepatic plates and adjacent sinusoids form associations that are structurally similar in all parts of the liver. Squamata livers had identical structures to that of the mammalian arrangement, which possesses higher metabolic functions. We speculated that these structural changes reflect the route of hepatic phylogenesis, and are essential for the acquisition of higher hepatic function.

Testudines and Crocodilia showed the two-cell-thick plate type, as observed in amphibians. Furthermore, the Black-headed sea snake (genus Hydrophis) showed the several-cell-thick plate type, with the livers having sinusoids of a primitive form, namely, narrow with an undeveloped network, identical to teleost livers. Reptiles breathe air and do not lay eggs underwater even though many species live in or around water, similar to amphibians. Since sea snakes live underwater, similar to fishes, their HSS resemble the primitive form of the teleost.

\section{Distribution of MMs in the liver}

Aggregations of pigmented cells, termed MMs, have been found in the livers of some fishes [8,9], amphibians [10-13], and reptiles [14-17]. Previous studies demonstrated that the pigmented cells of amphibian livers are cells belonging to the macrophage lineage of Kupffer cells [23-25] as well as the MMs centers of fishes [19,26,27]. In a recent review of melanin-synthesizing cells, Sichel et al. proposed a new classification for the pigmented cells in vertebrates derived from "hematopoietic stem cells" and including amphibian and reptilian Kupffer cells [24]. Although hematopoiesis has been examined extensively in mammals whose adult hematopoietic stem cells reside predominantly in the bone marrow [28], it is poorly understood in non-mammalian vertebrates. In amphibians, MMs are particularly numerous in the portal area [13], and hematopoietic tissue has been located in the portal triad and perihepatic subcapsular region in the orders Urodela and Gymnophiona; however, these were absent in the order Anura (except for the genus Xenopus) [6]. In contrast, there have been a few studies among each order in reptilians. In turtles, MMs were found to be distributed in the sinusoidal capillaries, and were of various sizes [16]. In the Nile crocodile [17] and other reptiles [29], large yellow-brown cytoplasmic phagosomes were detected in Kupffer cells located in hepatic lobules.

Our study of 23 species demonstrated that the expression of MMs exhibited heterogeneities related to the phylogenetic order. The patterns of these combinations were classified into three types: (A) PZ, IZ, and CZ, (B) PZ and IZ, and (C) IZ and CZ. In the orders

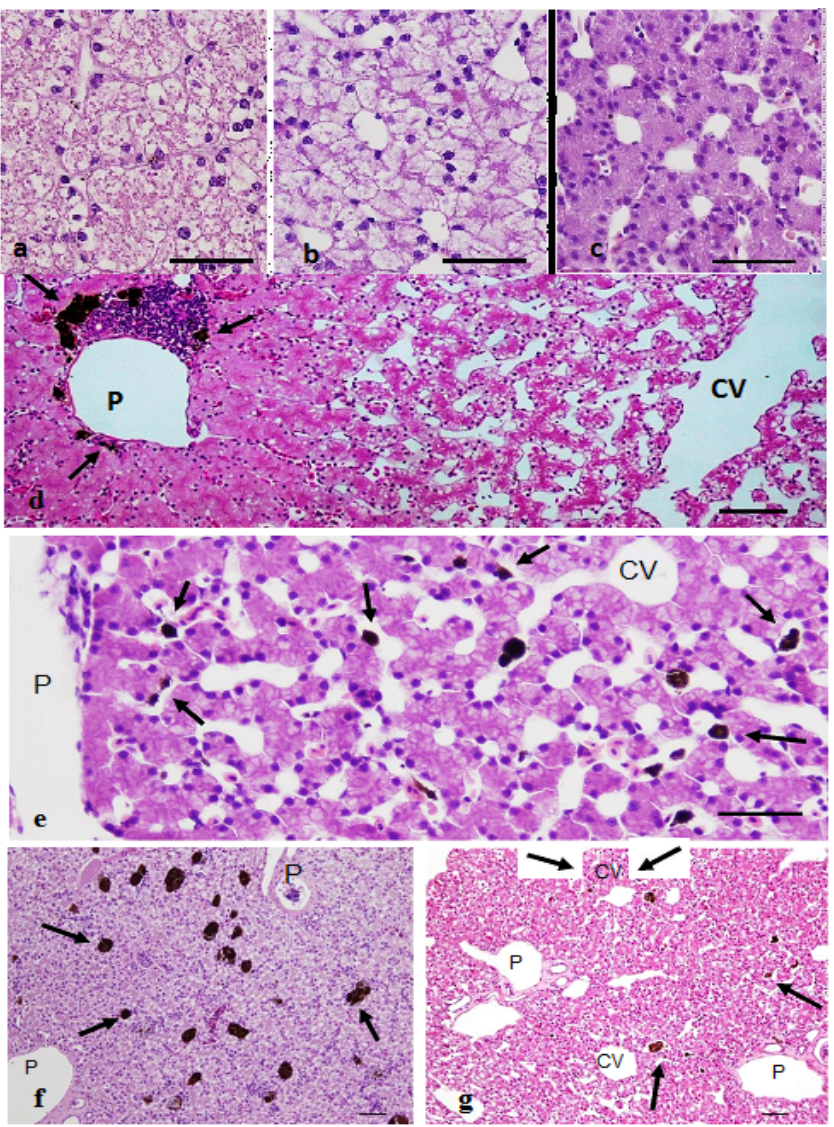

Figure 2: Light micrographs of the liver. Light micrographs of HHS and MMs in livers. (a) Several-cell-thick plate type. The hepatocyte lining is multi-layered. Hepatic sinusoids are narrow and short tortuous capillaries. The Black-headed sea snake (Hydrophis melanocephalus). (b) Two-cell-thick plate type. The hepatocyte lining is double-layered. Three to four hepatocytes surrounded a sinusoidal capillary. Japanese mamushi (Gloydius blomhoffii). (c) One-cellthick plate type. The hepatocyte lining is simple-layered. Hepatic sinusoids are enlarged. Japanese odd-tooth snake (Dinodon orientale). (d) HSS showed the combined one- and two-cell-thick plate types. $\mathrm{PZ}$ was the two-cell-thick plate type, whereas $\mathrm{IZ}$ and $\mathrm{CZ}$ were the one-cell-thick plate type and sinusoidal capillaries were enlarged. Peripheral sinusoids near terminal portal veins were tortuous, becoming straighter in the remainder of their course toward terminal central veins. MMs (arrows) were situated in the PZ and IZ. They were observed in sinusoidal capillaries, and various sizes existed. Red-eared slider (Trachemys scripta elegans). (e) HSS showed the one-cell-thick plate type. Sinusoidal capillaries were enlarged. MMs (arrows) were situated in the three zones (PZ, IZ, CZ). They were observed in sinusoidal capillaries, and small sizes existed. Japanese skink (Plestiodon japonicas). (f) MMs (arrows) were situated in the three zones (PZ, IZ, CZ). They were observed in sinusoidal capillaries, and large sizes existed. House gecko (Hemidactylus frenatus). (g) MMs (arrows) were situated in the $\mathrm{IZ}$ and $\mathrm{CZ}$. They were observed in brown cytoplasmic phagosomes, and were of a small size in sinusoidal capillaries. Sakishima grass lizard (Takydromus dorsalis). P: portal triads CV: central vein Scale bar $=50 \mu \mathrm{m}$. 
Testudines various sizes of MMs were observed in the hepatic lobules, with the distribution pattern of the category B type (PZ, and CZ).In the order Squamata, the suborder Lacertilia was observed in the MMs in the hepatic lobule, the distribution pattern was the category $\mathrm{B}$ or $\mathrm{C}$ type, and MMs were small. In the genus Hemidactylus and Plestiodon, the distribution of MMs was the category A type. MMs were larger and widely observed in the sinusoidal capillaries. MMs exist in most reptiles, but were not observed in the hepatic lobules of the suborder Serpentes with the exception of black-headed sea snakes. In the Blackheaded sea snake, the distribution of MMs was the category $\mathrm{C}$ type, they were smaller, and their number was lower in sinusoids. In the order Crocodilia, moderate sizes of MMs were observed in the hepatic lobules, with the distribution pattern of the category A type (PZ, IZ, and CZ). MMs were located in the IZ. IZ has been suggested to be an important zone relevant to the function of MMs in the livers of reptiles.

Reptilians are considered intermediate beings in the evolutionary passage of vertebrates from aquatic to dry land habitats. The occurrence of MMs may be related to the development of the immune system relevant to the spleen and bone marrow. Reptilians are ectotherms; their internal temperature varies according to the ambient environment. Furthermore, MMs are well developed in turtles, alligators, and sea snakes whose place of main habitation is underwater, suggesting that the development of their immune systems may be adapted according to ecological and behavioral patterns.

Histologically, MMs exhibited numerical and sizeable heterogeneities related to the phylogenetic order. Previous studies demonstrated that the content of melanin increased in amphibian livers during the winter $[10,30]$, in addition to metabolic and structural modifications in hepatocytes [10]. Other studies have reported that a relationship exists between the activation of hepatic melanogenesis and hypoxia in the newt [31]. Furthermore, a relationship has been hypothesized between increased liver pigmentation and hepatic hemocatheresis (Cicero et al., 1977, Kalashnikova, 1992). Regarding MM centers in fishes, increases in the melanic pigment have been described under particular disease conditions [32]. The impact of temperature on phagocytosis by these cells is currently unknown; however, one of the advantages of MMs for poikilotherms may be the maintenance of phagocytotic ability at low temperatures.

\section{Division of three zones in the acinus}

Blood flows from the afferent (portal vein) of the lobule through the sinusoid to its efferent (central vein). Rappaport divided the portalcentral (afferent-efferent) lengths of hepatic plates into three arbitrary zones (zones 1, 2, and 3). Zones 1, 2, and 3 represent areas supplied with blood of first, second, and third qualities, respectively, regarding oxygen and nutrients. These zones differ in their functional capabilities and susceptibilities to pathological damage [3].

The livers of mammals, birds, reptiles, amphibians, and fishes pass though similar developmental sequences, but vary structurally in adults [4]. Various liver cells show numerical, structural, and functional heterogeneities related to their location along the afferent-efferent axis of hepatic plates and sinusoids. These variations in structure and cellular composition are associated with functional differences among hepatocytes located at different points along the afferent-efferent axis of plates-sinusoids [3].

In amphibians, the traditional form was the combined two- and one-cell-thick plate type, and hematopoietic tissue structures were located in Glisson's sheath, the connective tissue of the portal triad, and perihepatic subcapsular regions [6]. In reptiles, the traditional form was the one-cell-thick plate type, and the distribution of MMs was observed in the three zones. However, MMs show numerical, size, and locational heterogeneities related to the phylogenetic order. The patterns of these combinations have been classified into three types: (a) PZ, IZ, and CZ, (b) PZ and IZ, and (c) IZ and CZ, and MMs were always observed at IZ in common with those species. Since the distribution of HSS and MMs was localized, Rappaport's zonal relationship may be differentiated in reptilian livers.

\section{Conclusion}

This study phylogenically investigated reptilian livers, and showed that the formation of parenchymal arrangements is acquired in the route of hepatic phylogenesis. The occurrence of MMs may be related to the development of the immune system relevant to hematopoietic tissue in the liver. The immune systems of turtles, alligators, and sea snakes, whose place of main habitation is underwater, may have adapted according to ecological and behavioral patterns. Based on the hepatic architecture of parenchymal arrangements and distribution of MMs, it was suggested that reptilian livers acquired the division of three zones in the acinus. In hepatic phylogenesis, we demonstrated that parenchymal arrangements formed phylogenically.

\section{Acknowledgment}

We thank Dr. Hiroyoshi Kohno and Mr. Ken Sakihara, the Okinawa Regional Research Center, Tokai University, for their help in this study. We thank Dr. Iguchi at the National Institute for Basic Biology for supplying the alligator sample.

\section{References}

1. Rappaport AM (1967) Anatomic considerations. Diseases of the Liver (Edn 2) 1-46. J B Lippincott Company, Philadelphia.

2. Motta PM (1984) The three-dimensional microanatomy of the liver. Arch Histol Jap 47: 1-30.

3. Rappaport AM (1973) The microcirculatory hepatic unit. Microvasc Res 6: 212228.

4. Elias $H$ (1955) Origin and early development of the liver. Various vertebrates Acta Hepatol 3: 1-567.

5. Akiyoshi H, Inoue A (2004) Comparative histological study of teleost livers in relation to phylogeny. Zool Sci 21: 841-850.

6. Akiyoshi H, Inoue A (2012) Comparative histological study of hepatic architecture in the three orders amphibian livers. Comp Hepatol.

7. Elias $H$, Bengelsdorf $H$ (1952) The structure of the liver of vertebrates. Acta Anat (Basel) 14: 297-337.

8. Agius C (1985) The melano-macrophage centres of fish: a review. Fish Immunology 85-105. Academic Press, Orlando.

9. Arciuli M, Brunetti A, Fiocco D (2015) A multidisciplinary study of the extracutaneous pigment system of European sea bass (Dicentrachus labrax L.). A possible relationship between kidney disease and dopa oxidase activity level. Fish Shellfish Immunol 42: 184-192.

10. Barni S, Bertone V, Croce AC et al. (1999) Increase in liver pigmentation during natural hibernation in some amphibians. J Anat 195: 19-25.

11. Corsaro C, Scalia M, Leotta N Mondio F, Sichel G (2000) Characterisation of Kupffer cells in some Amphibia. J Anat 196: 249-261.

12. Gallone A, Guida G, Maida I, Cicero R (2002) Spleen and liver pigmented macrophages of Rana esculenta L. A new melanogenic system? Pigment Cell Res 15: 32-40.

13. Sichel G, Scalia M, Corsaro C (2002) Amphibia Kupffer cells. Microsc Res Tech 57: 477-490.

14. Scalia M, Geremia E, Corsaro C (1988) The extracutaneous pigmentary system: evidence for the melanosynthesis in amphibia and reptilia liver. Comp Biochem Physiol 89B: 715-717.

15. Johnson JC, Schwiesow T, Ekwall AK, Christiansen JL (1999) Reptilian melanomacrophages function under conditions of hypothermia: observations 
Citation: Akiyoshi H, Inoue-Matsuo A ,Onodera I (2015) Comparative Histological Study of Parenchymal Arrangements in Three Orders of Reptilian Livers. J Phylogen Evolution Biol 4: 161. doi:10.4172/2329-9002.1000161

on phagocytic behavior. Pigment Cell Res 12: 376-382

16. Moura LR, Santos ALQ, Belleti ME Vieira (2009) Morphological aspects of the liver of the freshwater turtle Phrynops geoffroanus Schweigger, 1812 (Testudines, Chelidae). Braz J Morphol Sci 26: 129-134.

17. Wilpe E, Groenewald HB (2014) Kupffer cell structure in the juvenile Nile crocodile, Crocodylus niloticus. J Morph 275: 1-8.

18. Sichel $G$ (1998) Biosynthesis and function of melanins in hepatic pigmentary system. Pigment Cell Res 1: 250-258.

19. Zuasti A, Ferrer C, Aroca P, Solano F (1990) Distribution of extracutaneous melanin pigment in Sparus auratus, Mugil cephalus and Dicentrarchus labrax (Pisces, Teleostei). Pigment Cell Res 3: 126-131.

20. Petherick CJ, Duncan IJH, Erhard HW (2003) Guidelines for ethical use of animal behavioral science. Appl Anim Behav Sci 81: 291-305.

21. Speilberg L, Evensen O, Nafstad P (1964) Liver of juvenile atlantic salmon, Salmo salar L.: a light, transmission, and scanning electron microscopic study, with special reference to the sinusoid. Anat Rec 240: 291-307.

22. Cornelius CE (1985) Hepatic ontogenesis. Hepatology 5: 1213-1221.

23. Pintucci G, Manzionna M, Maida I (1990) Morpho-functional characterization of cultured pigment cells from Rana esculenta L. liver. Vitro Cell Dev Biol Anim 26: 659-664.

24. Sichel G, Scalia M, Mondio F, Corsaro C (1997) The amphibian Kupffer cells build and demolish melanosomes: an ultrastructural point of view. Pigment Cell Res 10: 271-287.
25. Guida G, Maida I, Gallone A, Boffoli M, Cicero R (1998) Ultrastructural and functional study of liver pigment cells from Rana esculenta L. Vitro Cell Dev Biol Anim 34: 393-400.

26. Agius C (1980) Phylogenetic development of melano-macrophage centers in fish. J Zool Lond 191: 11-31.

27. Zuasti A, Jara JR, Ferrer C, Solano F (1989) Occurrence of melanin granules and melanosynthesis in the Kidney of Sparus auratus. Pigment Cell Res 2: 93-99.

28. Huang X, Cho S, Spangrude GJ (2007) Hematopoietic stem cells: generation and self-renewal. Cell Death Differ 14:1851-1859.

29. Jacobson ER (2007) Overview of reptile biology, anatomy, and histology. Infectious Diseases and Pathology of Reptiles 1-130. CRC Press, Florida.

30. Corsaro C, Scalia M, Sinatra F, Sichel G (1990) Circannual rhythm of the melanin content in frog liver (Rana esculenta L). Pigment Cell Res 3: 120-122.

31. Frangioni G, Borgioli G, Bianchi S, Pillozzi S (2000) Relationships between hepatic melanogenesis and respiratory conditions in the newt, Triturus carnifex. J Exp Zool 287: 120-127.

32. Roberts RJ (1974) Melanin-containing cells of teleost fish and their relation to disease. Anatomic Pathology of Teleost Fish 339-428. University of Wisconsin press, Madison. 